\title{
Stanford Type A Aortic Dissection: a Complex Disease for Patients and Cardiothoracic Surgeons
}

\author{
Gabriele Maria Iacona* and Abeel A Mangi \\ Department of Cardiac Surgery, Yale University School of Medicine, Yale New Haven Hospital, New Haven, Connecticut, USA \\ *Corresponding author: Gabriele Maria Iacona, Department of Cardiac Surgery, Yale University School of Medicine, Yale New Haven Hospital, New \\ Haven, Connecticut, USA
}

Submission: December 13, 2017; Published: January 04, 2018

\begin{abstract}
Acute type A aortic dissection is a catastrophic event in which blood exits the vascular lumen and dissects the media, creating a false lumen. Surgery is the best possible treatment but it is complex. The surgical team needs to understand the anatomy and physiopathology before dealing with the repair. While there are just a few surgical solutions for the repair of the dissected ascending aorta, debate is still ongoing about the best surgical option for the disease involving the arch and the descending aorta. Late reoperations are relatively common on the aortic valve and/or the distal aorta after primary repair. Results are excellent in specialized centers with high volume and complexity. Lifelong follow-up is required in survivors.
\end{abstract}

Keywords: Aortic dissection; Intramural hematoma; Penetrating atherosclerotic ulcer; Acute aortic syndrome; Aortic rupture; Aortic surgery; Malperfusion

\section{Introduction}

Acute type A aortic dissection (AD) is a catastrophic event in which blood exits the vascular lumen and dissects the media, creating a false lumen. Incidence of acute aortic dissection ranges from 2 to 3.5/100.000 inhabitants, but incidence appears to be increasing [1-3], due to the improvement in diagnostics. Incidence in men is roughly twice than in women, and men are usually younger than women (mean age at presentation in men versus women 60.3 vs. 66.7 year) [4]. Variations of the incidence have been reported, with more dissections occurring in the winter versus the summer due an increase in systemic vascular resistance during the cold months, and more often in December, on Monday and between 6am and $12 \mathrm{pm}$ [5-7]. Mortality is $1-2 \%$ per hour for patients who do not undergo surgery, with half of the patients expected to be dead by the third day, and almost $80 \%$ by the end of the second week [8].

The focus of this mini-review is dissection of the ascending aorta (Stanford type A) in accordance to our experience and scientific literature.

\section{Pathophysiology}

The aorta has 3 layers: intima, media and adventitia. A single layer of endothelial cells supported by a loose connective-tissue sublayer represents the intima. The connective sublayer permits motion of the intima relative to the media when the aorta expands and contracts during the cardiac cycle. The media is composed of 50 layers of fenestrated, lamellar elastic fibers, with interposed collagenous fibers and smooth-muscle cells. Elastin is highly stretchable and permits the aorta to distend and be elastic. The collagenous fibers support aortic integrity and resist shearing forces. The adventitia is made of collagen and connective tissue that also contributes to aortic integrity. The vasa vasorum within the adventia provide nutritional circulation to the vascular wall. Aortic dissection is essentially a mechanical failure of the aortic wall. A degeneration process of the aortic media characterized by pooling of mucoid material (cystic medial necrosis), disruption of elastin lamellae (elastin fragmentation), increase in collagen at the expense of smooth muscle cells (fibrosis), and areas with apparent loss of nuclei (medionecrosis) affects the aortic media in 20\% of patients with $\mathrm{AD}$. These histological changes can intervene in some genetic disorders (Ehlers-Danlos, Marfan, Turner, Noonan, LoeysDietz and other familial thoracic syndromes), but are also normal consequences of aging [9]. Hypertension, tobacco abuse and structural aortic defects (aortic coartaction, BAV) can accelerate this process [10].

An intimal tear propagating within the media either proximally or distally is the primary etiology of aortic dissection. The tear can occurs anywhere in the aorta but more frequently in the ascending portion. The blood will flow predominantly in a new lumen called "false lumen" separated from the true lumen by a thin intimal flap and contained by the aortic adventitia. The false lumen may propagates propagate proximally all the way to the aortic valve and 
distally in a spiraled (most often) or straight manner. Often the true lumen becomes compressed by the false lumen leading to ischemic complications [11]. Unfortunately this process can interest any of the branches of the aorta originating from the aortic valve to the iliac bifurcation and malperfusion may occur, unless a communication between the true lumen and the false lumen re-establishes normal blood flow. A dreadful consequence of $\mathrm{AD}$ is acute aortic rupture in the pericardial sac (pericardial tamponade), in the pleura (hemothorax), or less commonly in the abdomen (retroperitoneal hemorrhage). When, AD progresses proximally towards the aortic valve annulus, the aortic valve leaflets lose their supports and an acute aortic regurgitation develops. Death occurs because aortic rupture, neurological deficit, visceral ischemia/kidney failure and cardiac tamponade [12].

It is important to acknowledge the presence of some other variants of aortic disease known as intramural hemorrhage (IMH) and penetrating aortic ulcer (PAU) linked through a common pathogenesis. The "primum movens" of the IMH is slightly different from $\mathrm{AD}$ : the point of entry for blood into the media may be the rupture of vasa vasorum causing a lumen rupture and a free communication between the true lumen and the tear [13]. There is also evidence of that IMH may originate from an intimal tear similar to AD [14]. It may be considered a thrombosed AD or its precursor. In fact, IMH evolves into full AD (with a double-barrel aorta) in nearly $20 \%$ of cases. Two thirds of intramural hematomas involve the descending aorta (rather than the ascending aorta) [15]. PAU is primarily a disease of the intima, a condition where an atherosclerotic lesion with ulceration erodes into the internal elastic lamina (media) [16]. The ulcer can precede $\mathrm{AD}$ and be associated with intramural hematoma. Penetrating aortic ulcers can form anywhere along the aorta, more frequently in the descending thoracic portion.

Risk factors for the development of acute AD are male sex, age in the 60s and 70s, hypertension, prior cardiac surgery (particularly aortic valve repair), bicuspid aortic valve, and a history of Marfan syndrome. Less than $10 \%$ of the time, acute AD occurs in patients younger than age 40 , often normotensive, with a history of cardiac surgery or a bicuspid aortic valve, Marfan syndrome, Ehlers-Danlos syndrome, or similar conditions [3]. Traumatic aortic dissection as a consequence of road traffic accidents or deceleration trauma has been reported also [17-19]. The chronic use of cocaine appears to predispose patients to $\mathrm{AD}[20]$.

\section{Clinical Presentation}

Since AD, IMH, and PAU share common pathogenetic mechanisms and clinical features they have been considered as a sort of unique "ensemble" known as "acute aortic syndrome" (AAS) [21]. Sudden onset, severe chest and/or back pain are the most commonly presenting symptoms, regardless of the underlying condition (AD, IMH, and PAU). Tearing or ripping pain often starts in the chest and migrates to the back or epigastrium. Painless AD has been reported also [22]. Physical examinations shows signs of distress or shock. Patient is pale or diaphoretic. Blood pressure can be normal and sudden appearance of hypotension should be considered as an alarm for ruptured aorta. Others findings are pulse deficits, new diastolic murmur, signs of myocardial ischemia, pericardial friction rubs, distended jugular veins, neurological deficits, altered level of consciousness and stroke [23].

\section{Diagnosis}

In most circumstances a chest CT scan with intravenous contrast will be sufficient to make diagnosis of $\mathrm{AD}$ (sensitivity approaches $100 \%$ and specificity is $98 \%$ ) [24]. In unstable patients a transthoracic echocardiogram is a useful tool for rapid evaluation of $\mathrm{AD}$ and it does not require any nephrotoxic contrast, but it has limitations in assessing distal ascending aorta, aortic arch and descending thoracic aorta. Trans-esophageal echocardiogram is mainly used in OR, being more invasive. MRI is employed as a confirmatory test and in follow-up [25]. Coronary angiography is controversial because delays surgical treatment and needs intravenous contrast.

\section{Classification}

On the basis of the image studies, AD is classified according to extent and acuity. Stanford classification is probably the easiest and most widely adopted: type A includes all dissections in which the ascending aorta is involved and it requires urgent surgical treatment; type B includes all dissections with only involvement of the descending aorta and it requires either medical or surgical treatment [26]. Tear occurs in the ascending aorta 57\% of cases, in the arch $10 \%$, near the origin of the subclavian artery in $5 \%$ of cases; in type B it is located just below the origin of the subclavian artery in $23 \%$ of cases, distal to origin of the subclavian artery in $3 \%$ of cases, in the abdominal aorta in $2 \%$ of cases [23].

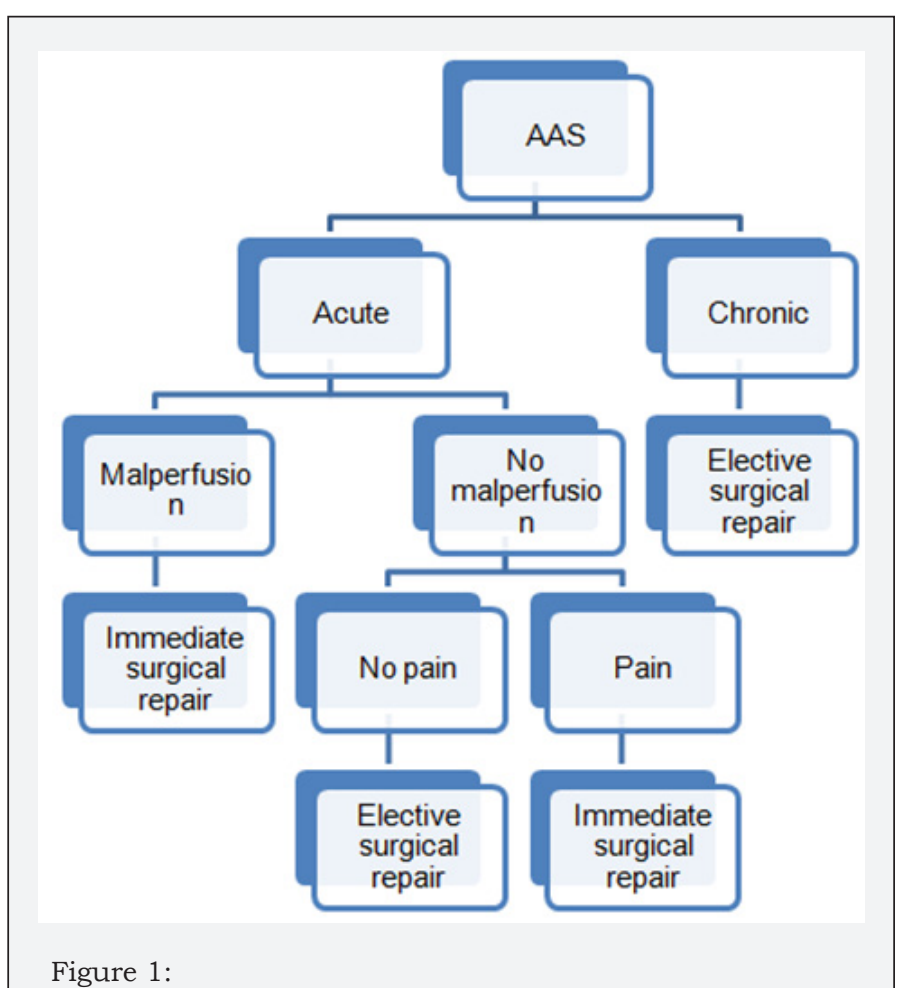


DeBakey classification uses origin and extent of AD: type I originates from the root and extends into the descending thoracic and thoracoabdominal aorta, type II is limited to the ascending aorta, type IIIA is limited to the descending thoracic aorta, and type IIIB is limited to the thoracoabdominal aorta [27].

$\mathrm{AD}$ is classified as acute when it has been present and ongoing for less than 2 weeks, and as chronic in all other cases. Again acute $\mathrm{AD}$ requires either immediate or urgent surgical treatment.

On the basis of the information previously reported, the authors propose the following algorithm (Figure 1):

\section{Preoperative management}

For Stanford type A aortic dissection, surgical repair is the mainstay of treatment. It is mandatory to perform an accurate assessment of the patient's preoperative risk for determining the adequate surgical option, the optimal postoperative care, and for predicting the surgical outcome.

Preparation for the intervention requires transfer to a medical center with experience in management of $\mathrm{AD}$, admission to ICU, and invasive arterial blood pressure monitoring [28,29]. Medical treatment called "anti-impulse therapy" is directed toward avoidance of aortic rupture and reduction of further propagation of the dissection by control of blood pressure and $\mathrm{dP} / \mathrm{dt}$ (pressure development). Intravenous $\beta$ blockers are the first line therapy. Their use seems to be associated with improved outcome in type A in patients with type A AD [30,31]. Goals to be achieved are: systolic blood pressure 100-120mmHg, mean blood pressure between $60-75 \mathrm{mmHg}$, and heart rate $60-80 \mathrm{bpm}$ [32]. Pure vasodilators may be added to the treatment, but attention must be directed towards avoidance of reflex tachycardia. Excessive falls in pressure may precipitate renal, cerebral or coronary ischemia Volume resuscitation should be used in hypotensive patients. Opioid analgesia is used to treat discomfort and pain-Quite. Quite environment is also required in this stressful circumstance.

\section{Surgical Results}

Successful surgical repair was first attempted in 1955 by DeBakey, Cooley, and Creech [33]. Goals of the Stanford type A aortic dissection repair are prevention of aortic rupture, restoration of valve competency, treatment of coronary malperfusion, treatment of cerebral malperfusion, and restoration of optimal systemic blood flow through the true lumen.

Mortality rate associated with surgical treatment of a dissected ascending aorta (Stanford type A) is between 10 and 30 percent [29,34-38]. Independent preoperative predictors of poor outcome after repair of Stanford type A aortic dissection are age greater than 70 years, prior cardiac surgery, hypotension (systolic blood pressure less than $100 \mathrm{mmHg}$ ) or shock at presentation, migrating pain, cardiac tamponade, any pulse deficit, and electrocardiogram with findings of myocardial ischemia or infarction [39]. Generalized and localized ischemia seem to have a major role as preoperative predictors of intraoperative and in-hospital mortality [40,41]. In hospital mortality is $30.5 \%$ in patients presenting with any malperfusion syndrome, while patients without malperfusion syndrome have only $6.2 \%$. Presence of any malperfusion is associated with increased occurrence of postoperative complications (coma, delirium, sepsis, renal failure, MI, acute limb ischemia, and multiple organ failure). Cerebral malperfusion is associated with high rates of postoperative stroke (46.7\%) and poor survival at 10 years (12.5\%). Restoring normal blood flow in the true lumen is the best possible solution for treating malperfusion syndrome; hence surgery should never be delayed [42-45].

Contemporary surgery are 1- and 3-year survival of patients with Stanford type A AD treated with $96.1 \%$ and $90.5 \%$ versus $88.6 \%$ and $68.7 \%$ in patients with medical treatment of $\mathrm{AD}$. Independent predictors of survival (atherosclerosis and previous cardiac surgery) during the follow-up period do not appear to be influenced by in-hospital risks but rather preexisting comorbidities [46].

Late reoperations are relatively common. Rate for aortic valve re-intervention is $2.1 \%$ /patient-year after conservative approach because of recurrence of aortic valve insufficiency. Many authors consider severe aortic regurgitation at the time of surgery a significant risk factor for re-intervention during the long follow-up of hospital survivors [35, 46, 47]. Hence, an aggressive approach on the root (aortic root replacement) has been proposed in patients deemed at high risk for late aortic complications and reinterventions [49-51]. Other studies found no difference in longterm survival in patients treated with either a conservative (valve resuspension) or more aggressive approach and no difference in freedom of reoperation on the aortic root or valve among different operations $[47,52]$.

Multiple series have noted the significant combination of distal reoperation requirement, aortic related death, and the growth of the downstream aorta after the repair. Patency of the false lumen in the descending aorta remains a major risk factor for adverse long-term outcomes [53]. There is an increasing tendency for more aggressive surgery including antegrade stent deployment in the descending thoracic aorta at the time of open aortic arch repair [5457]. Distal false lumen obliteration is achieved in the vast majority of cases [56-58]. However, this approach has not yet been proven to be the procedure of choice, is certainly more complex, poses higher risk for patients and should be performed in high volumes centres [59-63].

Patients surviving an AD require lifelong follow-up with MRI or CT scan. Common practice is to ask for CT scan with intravenous contrast before hospital discharge, at 3 and 9 months after discharge, and yearly or more frequently depending on the size of the aorta. Blood pressure control is mandatory because reoperation rate may decrease with improved systolic blood pressure [64].

\section{Conclusion}

Despite the advances in the surgical field, $\mathrm{AD}$ remains a challenge both for the patient and the surgical team. A high degree of clinical suspicion is required for a rapid diagnosis. Imaging is of 
paramount importance in differentiating among AD, IMH, and PAU. Keeping in mind that primary goal in this complex disease is patient survival and there is no benefit with only medical treatment, surgery should never be delayed. Surgery is complex and the surgeon needs to understand the anatomy and physiopathology of the aortic dissection before dealing with such a complex disease. While there are just few surgical solutions for the repair of the dissected ascending aorta, debate is still ongoing about the best surgical solution for the disease involving the arch and the descending aorta, especially if he intimal extends into the thoraco-abdominal aorta. Surgery should be probably performed in institutions with experience in the management of $\mathrm{AD}$, where patient volume and complexity is higher. Aortic surgeons report excellent mortality but the question about the best solution for the residual dissection after repair is still without answer.

\section{References}

1. Clouse WD, Hallett JW, Schaff HV, Spittell PC, Rowland CM,et al. (2004) Acute aortic dissection: population-based incidence compared with degenerative aortic aneurysm rupture. Mayo Clin Proc 79(2): 176-180.

2. Olsson C, Thelin S, Ståhle E, Ekbom A, Granath F (2006) Thoracic aortic aneurysm and dissection: increasing prevalence and improved outcomes reported in a nationwide population-based study of more than 14,000 cases from 1987 to 2002. Circulation 114(24): 2611-2618.

3. Hagan PG, Nienaber CA, Isselbacher EM, Bruckman D, Karavite DJ, et al. (2000) The International Registry of Acute Aortic Dissection (IRAD): new insights into an old disease. JAMA 283(7): 897-903.

4. Nienaber CA, Fattori R, Mehta RH, Richartz BM, Evangelista A, et al. (2004) International Registry of Acute Aortic Dissection. Gender-related differences in acute aortic dissection. Circulation 109(24): 3014-3021.

5. Takagi H, Ando T, Umemoto T (2017) Meta-Analysis of Seasonal Incidence of Aortic Dissection. Am J Cardiol 120(4): 700-707.

6. DeAnda A, Grossi EA, Balsam LB, Moon MR, Barlow CW, et al. (2015) The Chronobiology of Stanford Type A Aortic Dissections: A Comparison of Northern versus Southern Hemispheres. Aorta (Stamford) 3(6): 182-186.

7. Vitale J, Manfredini R, Gallerani M, Mumoli N, Eagle KA, et al. (2015) Chronobiology of acute aortic rupture or dissection: a systematic review and a meta-analysis of the literature. Chronobiol Int 32(3): 385-394.

8. Coady MA, Rizzo JA, Goldstein LJ, Elefteriades JA (1999) Natural history, pathogenesis, and etiology of thoracic aortic aneurysms and dissections. Cardiol Clin 17(4): 615-635.

9. Schlatmann TJ, Becker AE (1977) Pathogenesis of dissecting aneurysm of aorta. Comparative histopathologic study of significance of medial changes. Am J Cardiol 39(1): 21-26.

10. Larson EW, Edwards WD (1984) Risk factors for aortic dissection: a necropsy study of 161 cases. Am J Cardiol 53(6): 849-855.

11. Lundevall J (1964) Traumatic rupture of the aorta, with special reference to road accidents. Acta Pathol Microbiol Scand 62: 29-33.

12. Sastry P, Field M, Cuerden R, Richens D (2010) Low-impact scenarios may account for two-thirds of blunt traumatic aortic rupture. Emerg Med J 27(5): 341-344.

13. Di Marco L, Pacini D, Di Bartolomeo R (2013) Acute Traumatic Thoracic Aortic Injury: Considerations and Reflections on the Endovascular Aneurysm Repair. Aorta (Stamford) 1(2):117-122.

14. Dean JH, Woznicki EM, O'Gara P, Montgomery DG, Trimarchi S, et al. (2014) Cocaine-related aortic dissection: lessons from the International

\section{Registry of Acute Aortic Dissection. Am J Med 127(9): 878-885.}

15. Roberts WC (1981) Aortic dissection: anatomy, consequences, and causes. Am Heart J 101(2): 195-214.

16. Mehta RH, Suzuki T, Hagan PG, Bossone E, Gilon D, et al. (2002) Predicting death in patients with acute type a aortic dissection. Circulation 105(2): 200-206.

17. Coady MA, Rizzo JA, Hammond GL, Pierce JG, Kopf GS, (1998) Penetrating ulcer of the thoracic aorta: what is it? How do we recognize it? How do we manage it? J Vasc Surg 27(6): 1006-1015; discussion 1015-1016.

18. Uchida K, Imoto K, Karube N, Minami T, Cho T, et al. (2013) Intramural haematoma should be referred to as thrombosed-type aortic dissection. Eur J Cardiothorac Surg 44(2): 366-369.

19. Evangelista A, Mukherjee D, Mehta RH, O'Gara PT, Fattori R, et al. (2005) International Registry of Aortic Dissection (IRAD) Investigators. Acute intramural hematoma of the aorta: a mystery in evolution. Circulation 111(8): 1063-1070.

20. Stanson AW, Kazmier FJ, Hollier LH, Edwards WD, Pairolero PC, et al. (1986) Penetrating atherosclerotic ulcers of the thoracic aorta: natural history and clinicopathologic correlations. Ann Vasc Surg 1(1): 15-23.

21. Nienaber CA, Powell JT (2011) Management of acute aortic syndromes. Eur Heart J 33(1): 26-35b.

22. Park SW, Hutchison S, Mehta RH, Isselbacher EM, Cooper JV, et al. (2004) Association of painless acute aortic dissection with increased mortality. Mayo Clin Proc 79(10): 1252-1257.

23. Gallo A, Davies RR, Coe MP, Elefteriades JA, Coady MA (2005) Indications, timing, and prognosis of operative repair of aortic dissections. Semin Thorac Cardiovasc Surg 17(3): 224-235.

24. Shiga T, Wajima Z, Apfel CC, Inoue T, Ohe Y (2006) Diagnostic accuracy of transesophageal echocardiography, helical computed tomography, and magnetic resonance imaging for suspected thoracic aortic dissection: systematic review and meta-analysis. Arch Intern Med 166(13): 13501356.

25. Nienaber CA, Eagle KA (2003) Aortic dissection: new frontiers in diagnosis and management: Part I: from etiology to diagnostic strategies. Circulation 108(5): 628-635.

26. Daily PO, Trueblood HW, Stinson EB, Wuerflein RD, Shumway NE (1970) Management of acute aortic dissections. Ann Thorac Surg 10(3): 237247.

27. Debakey Me, Henly Ws, Cooley Da, Morris Gc Jr, Crawford Es, et al. (1965) Surgical Management Of Dissecting Aneurysms Of The Aorta. J Thorac Cardiovasc Surg 49: 130-149.

28. Geirsson A, Ahlsson A, Franco-Cereceda A, Fuglsang S, Gunn J, et al. (2017) Hospital volumes and later year of operation correlates with better outcomes in acute Type A aortic dissection. Eur J Cardiothorac Surg 53(1): 276-281.

29. Chikwe J, Cavallaro P, Itagaki S, Seigerman M, Diluozzo G, et al. (2013) National outcomes in acute aortic dissection: influence of surgeon and institutional volume on operative mortality. Ann Thorac Surg 95(5): $1563-1569$

30. Suzuki T, Isselbacher EM, Nienaber CA, Pyeritz RE, Eagle KA, et al. (2012) Type-selective benefits of medications in treatment of acute aortic dissection (from the International Registry of Acute Aortic Dissection [IRAD]). Am J Cardiol 109(1): 122-127.

31. Lederle FA, Powell JT, Nienaber CA (2014) Does intensive medical treatment improve outcomes in aortic dissection? BMJ 349: g5288.

32. Nienaber CA, Powell JT (2012) Management of acute aortic syndromes. Eur Heart J 33(1): 26-35b.

33. Bavaria JE, Brinster DR, Gorman RC, Woo YJ, Gleason T, et al. (2002) Ad- 
vances in the treatment of acute type A dissection: an integrated approach. Ann Thorac Surg 74(5): S1848-S1852; discussion S1857-1863.

34. Sabik JF, Lytle BW, Blackstone EH, McCarthy PM, Loop FD, et al. (2000) Long-term effectiveness of operations for ascending aortic dissections. J Thorac Cardiovasc Surg 119(5): 946-962.

35. Russo CF, Mariscalco G, Colli A, Santè P, Nicolini F, et al. (2016) Italian multicentre study on type A acute aortic dissection: a 33-year follow-up. Eur J Cardiothorac Surg 49(1): 125-131.

36. Trimarchi S, Nienaber CA, Rampoldi V, Myrmel T, Suzuki T, et al. (2005) Contemporary results of surgery in acute type A aortic dissection: The International Registry of Acute Aortic Dissection experience. J Thorac Cardiovasc Surg 129(1): 112-122.

37. Olsson C, Ahlsson A, Fuglsang S, Geirsson A, Gunn J, et al. (2017) Medium-term survival after surgery for acute Type A aortic dissection is improving. Eur J Cardiothorac Surg 52(5): 852-857.

38. Rampoldi V, Trimarchi S, Eagle KA, Nienaber CA, Oh JK, et al. (2007) Simple risk models to predict surgical mortality in acute type A aortic dissection: the International Registry of Acute Aortic Dissection score. Ann Thorac Surg 83(1): 55-61.

39. Augoustides JG, Geirsson A, Szeto WY, Walsh EK, Cornelius B, et al (2009) Observational study of mortality risk stratification by ischemic presentation in patients with acute type A aortic dissection: the Penn classification. Nat Clin Pract Cardiovasc Med 6(2): 140-146.

40. Augoustides JG, Szeto WY, Desai ND, Pochettino A, Cheung AT, et al. (2011) Classification of acute type A dissection: focus on clinical presentation and extent. Eur J Cardiothorac Surg 39(4): 519-522.

41. Geirsson A, Szeto WY, Pochettino A, McGarvey ML, Keane MG, et al (2007) Significance of malperfusion syndromes prior to contemporary surgical repair for acute type A dissection: outcomes and need for additional revascularizations. Eur J Cardiothorac Surg 32(2): 255-262.

42. Olsson C, Hillebrant CG, Liska J, Lockowandt U, Eriksson P, et al. (2011) Mortality in acute type A aortic dissection: validation of the Penn classification. Ann Thorac Surg 92(4): 1376-1382.

43. Kimura N, Ohnuma T, Itoh S, Sasabuchi Y, Asaka K, et al. (2014) Utility of the Penn classification in predicting outcomes of surgery for acute type a aortic dissection. Am J Cardiol 113(4): 724-730.

44. Harris KM, Strauss CE, Eagle KA, Hirsch AT, Isselbacher EM, et al. (2011) Correlates of delayed recognition and treatment of acute type A aortic dissection: the International Registry of Acute Aortic Dissection (IRAD). Circulation 124(18): 1911-1918.

45. Tsai TT, Evangelista A, Nienaber CA, Trimarchi S, Sechtem U, et al. (2006) Long-term survival in patients presenting with type A acute aortic dissection: insights from the International Registry of Acute Aortic Dissection (IRAD). Circulation 114(1 Suppl): I350-I356.

46. Bekkers JA, Raap GB, Takkenberg JJ, Bogers AJ (2013) Acute type A aortic dissection: long-term results and reoperations.

Eur J Cardiothorac Surg 43(2): 389-396.

47. Kirsch M, Soustelle C, Houël R, Hillion ML, Loisance D (2002) Risk factor analysis for proximal and distal reoperations after surgery for acute type A aortic dissection. J Thorac Cardiovasc Surg 123(2): 318-325.

48. Di Eusanio M, Trimarchi S, Peterson MD, Myrmel T, Hughes GC, et al. (2014) Root replacement surgery versus more conservative management during type A acute aortic dissection repair. Ann Thorac Surg 98(6): 2078-2084.
49. Castrovinci S, Pacini D, Di Marco L, Berretta P, et al. (2016) Surgical management of aortic root in type A acute aortic dissection: a propensity-score analysis. Eur J Cardiothorac Surg 50(2): 223-229.

50. Esaki J, Leshnower BG, Binongo JN, Lasanajak Y, McPherson L, et al. (2017) Risk Factors for Late Aortic Valve Dysfunction After the David V Valve-Sparing Root Replacement. Ann Thorac Surg 104(5): 1479-1487.

51. Peterss S, Dumfarth J, Rizzo JA, Bonaros N, Fang H, et al. (2016) Sparing the aortic root in acute aortic dissection type A: risk reduction and restored integrity of the untouched root. Eur J Cardiothorac Surg 50(2): 232-239.

52. Geirsson A, Bavaria JE, Swarr D, Keane MG, Woo YJ, et al. (2007) Fate of the residual distal and proximal aorta after acute type a dissection repair using a contemporary surgical reconstruction algorithm. Ann Thorac Surg 84(6): 1955-1964; discussion 1955-1964.

53. Easo J, Weigang E, Hölzl PP, Horst M, Hoffmann I, Blettner M, et al. (2012) Influence of operative strategy for the aortic arch in DeBakey type I aortic dissection: analysis of the German Registry for Acute Aortic Dissection Type A. J Thorac Cardiovasc Surg 144(3): 617-623.

54. Tsagakis K, Pacini D, DiBartolomeo R, Gorlitzer M, Weiss G, et al. (2010) Multicenter early experience with extended aortic repair in acute aortic dissection: is simultaneous descending stent grafting justified? J Thorac Cardiovasc Surg 140: S116-120; discussion S142-S146.

55. Di Bartolomeo R, Pantaleo A, Berretta P, Murana G, Castrovinci S, et al. (2015) Frozen elephant trunk surgery in acute aortic dissection. J Thorac Cardiovasc Surg 149(2 Suppl): S105-109.

56. Kobayashi M, Chaykovska L, van der Loo B, Nguyen TD, Puippe G, et al. (2016) Long-term results of simplified frozen elephant trunk technique in complicated acute type A aortic dissection: A case-control study. Vascular 24(5): 523-30.

57. Weiss G, Santer D, Dumfarth J, Pisarik H, Harrer ML, et al. (2016) Evaluation of the downstream aorta after frozen elephant trunk repair for aortic dissections in terms of diameter and false lumen status. Eur J Cardiothorac Surg 49(1): 118-124.

58. Roselli EE, Rafael A, Soltesz EG, Canale L, Lytle BW (2013) Simplified frozen elephant trunk repair for acute DeBakey type I dissection. J Thorac Cardiovasc Surg 145(3 Suppl): S197-201.

59. Shrestha M, Fleissner F, Ius F, Koigeldiyev N, Kaufeld T, et al. (2015) Total aortic arch replacement with frozen elephant trunk in acute type A aortic dissections: are we pushing the limits too far? Eur J Cardiothorac Surg 47(2): 361-366.

60. Di Eusanio M, Castrovinci S, Tian DH, Folesani G, Cefarelli M, et al. (2014) Antegrade stenting of the descending thoracic aorta during DeBakey type 1 acute aortic dissection repair. Eur J Cardiothorac Surg 45(6): 967975.

61. Takagi H, Umemoto T (2016) A Meta-Analysis of Total Arch Replacement With Frozen Elephant Trunk in Acute Type A AorticDissection. Vasc Endovascular Surg 50(1): 33-46.

62. Elefteriades JA (2002) What operation for acute type A dissection? J Thorac Cardiovasc Surg 123(2): 201-203.

63. Melby SJ, Zierer A, Damiano RJ Jr, Moon MR (2013) Importance of blood pressure control after repair of acute type a aortic dissection: 25-year follow-up in 252 patients. J Clin Hypertens (Greenwich) 15(1): 63-68.

64. Melby SJ, Zierer A, Damiano RJ Jr, Moon MR (2013) Importance of blood pressure control after repair of acute type a aortic dissection: 25-year follow-up in 252 patients. J Clin Hypertens (Greenwich) 15(1): 63-68. 